\title{
Quality of life of parents of very preterm infants 4 months after birth: a mixed methods study
}

\author{
Mariana Amorim ${ }^{1,2,3^{*}}$, Elisabete Alves ${ }^{1,2}$, Michelle Kelly-Irving ${ }^{4,5}$, Ana Isabel Ribeiro ${ }^{1,2}$ and Susana Silva ${ }^{1,2}$
}

\begin{abstract}
Background: Knowledge about parental quality of life (QoL) is paramount to family-centred and integrated healthcare on prematurity, but evidence is limited. We aimed to explore mothers' and fathers' perspectives about their QoL 4 months after a very preterm childbirth.

Methods: This is a cross-sectional mixed methods study using a convergent design. Parents of very preterm infants were systematically recruited at all level III neonatal intensive care units in the Northern health region of Portugal for one year. Four months after childbirth, 61 mothers and 56 fathers filled-in the World Health Organization Quality of Life - BREF Inventory, and 26 couples were interviewed. Linear regression models were computed to assess the association between participants' characteristics and the QoL. Qualitative data were thematically analysed.
\end{abstract}

Results: A quantitative analysis revealed that the perception of QoL was not significantly different by gender. QoL scores increased slightly from the environment (Mean (SD): 72.1 (14.2)) to the psychological domains (Mean (SD): 78.7 (14.4)). All scores were influenced by psychological characteristics. Socioeconomic position influenced both parents' perceptions concerning the environment domain, and maternal physical and psychological QoL. Infant-related factors were associated with overall QoL among women and with the physical, psychological, social and environment domains among men. Qualitative findings indicated accommodation mechanisms that intertwine the focus on constraining factors (surveillance, sleep disturbances, non-supportive healthcare policies, hygienization) with facilitating factors (social support, accessibility/ quality of healthcare, opportunities for developing parental skills). These processes were anchored in child-centredness and a framework that construct hierarchies of hope and expectations about infant's health and development.

Conclusions: To capture parental QoL using mixed methods raises awareness for developing intersectoral family-centred policies, integrated health services and focused-interventions to decrease the disempowering effects of surveillance and hygienization.

Keywords: Quality of life, Parents, Very preterm birth, Family-integrated care, Mixed methods

\section{Background}

Preterm birth is a major public health issue. Its complications constitute one of the leading causes of global deaths among children under 5 years of age [1], and preterm infants are at high risk of neonatal morbidity [2]. Globally, the average preterm birth rate in 2010 was estimated at

\footnotetext{
* Correspondence: mariana.amorim@ispup.up.pt

${ }^{1}$ EPIUnit - Instituto de Saúde Pública, Universidade do Porto, Rua das Taipas, $n^{\circ} 135,4050-600$ Porto, Portugal

²Departamento de Ciências da Saúde Pública e Forenses e Educação Médica, Faculdade de Medicina, Universidade do Porto, Al. Prof. Hernâni Monteiro, 4200 - 319 Porto, Portugal

Full list of author information is available at the end of the article
}

$11.1 \%$, corresponding to more than one in ten of all births [3], and about $1 \%$ were a very preterm birth, occurring before 32 gestational weeks [4]. Despite medical and technological advances, infants born very preterm remain at high risk of death and neurodevelopmental impairment, with studies revealing an average of crude in-hospital mortality rates of $14.2 \%$ in 10 European regions [5, 6]. A very preterm delivery and the ensuing child's hospitalization in a Neonatal Intensive Care Unit (NICU) is considered a disruptive and stressful life event, affecting parental QoL via multiple pathways $[7,8]$, in a context with wide differences between

(c) The Author(s). 2018 Open Access This article is distributed under the terms of the Creative Commons Attribution 4.0 International License (http://creativecommons.org/licenses/by/4.0/), which permits unrestricted use, distribution, and reproduction in any medium, provided you give appropriate credit to the original author(s) and the source, provide a link to the Creative Commons license, and indicate if changes were made. The Creative Commons Public Domain Dedication waiver (http://creativecommons.org/publicdomain/zero/1.0/) applies to the data made available in this article, unless otherwise stated. 
the support to family-friendly and gender-equality policies in Western and Nordic European countries [9].

The literature consistently shows that the quality of life (QoL) of parents of preterm infants may be compromised by sleep disturbances, fatigue, stress and psychiatric symptoms [10-14], while being protected by a stable marital union, support and information provided by medical staff, partner, extended family and other parents of preterm children [14, 15]. This knowledge is essential to develop family-centred and integrated healthcare services and policies on prematurity $[16,17]$, an approach with benefits for parents, children and their families $[18,19]$ as well as for healthcare staff and health services [20].

However, studies exploring the intertwining of constraining and protective factors in the perception of QoL are scarce and focused on patients with chronic conditions [21]. Furthermore, there is still limited evidence about the impact of a preterm delivery on parental QoL, in a context where methodological heterogeneity is observed regarding the operationalization of QoL and the use of units of analysis (mothers, parents, families and caregivers) [22]. Finally, the influence of fathers' characteristics and structural factors (e.g., parental leave policies) on parental QoL after a preterm delivery has not been sufficiently addressed in previous research [22].

Further studies are thus needed to explore both maternal and paternal QoL, in the analysis of the individual, familial and societal factors influencing QoL. Such in-depth parental perspectives are key, especially during the return-to-work period, which is a relevant moment in countries where few attempts are being made to support parental leave $[23,24]$. A mixed methods approach would provide a more complete comprehension of the QoL questionnaires' scores, contributing to accurately capture the singular experience of parenting a very preterm infant [25] and the complexity of QoL assessment [26]. By integrating quantitative and qualitative data, this study aims to explore mothers' and fathers' perspectives about their own QoL, 4 months after a very preterm delivery.

\section{Methods}

This observational and cross-sectional mixed methods study used a convergent design aiming to merge quantitative and qualitative data into one overall interpretation, in which the quantitative results were validated or expanded with the qualitative data [27, 28]. This single-phase design (i.e. the quantitative and qualitative methods were implemented during the same timeframe and with equal weight) was chosen with the intention to best understand the QoL of parents of very preterm infants during the return-to-work period, ending up with well-substantiated conclusions about the factors that influence such phenomenon.
Between July 2013 and June 2014, all mothers and fathers of very preterm infants, admitted to all level III NICU located in the Northern Health Region of Portugal $(n=7)$, were consecutively and systematically invited to participate in the study by the healthcare team, 15 to 22 days after delivery. Parents who were present in the NICU during the hospitalisation period, who were able to speak and write in Portuguese, and those whose single or twin infants survived were considered eligible to participate in the study [29]. Among the 122 families invited, $96 \%$ agreed to participate in the evaluation at 4 months after delivery, the common return-to-work period in Portugal, in particular for mothers.

Clinical records were reviewed to retrieve data on pregnancy complications, multiple pregnancy, and infant's gestational age and birth weight. Extremely low birth weight was defined as birth weight bellow $1000 \mathrm{~g}$ and extremely premature infants were those with gestational age under 28 weeks $[4,30]$.

\section{Quantitative study: Participants and data collection}

Parents were contacted 4 months after delivery to confirm the availability to receive the questionnaires at home. Parents whose infants were still hospitalized $(n=1)$ or died $(n=3)$ were excluded from the study. Self-administered questionnaires to be completed individually, with prepaid return envelops, were sent by postal mail to 113 families. Among these, 67 mothers and 64 fathers completed and returned the questionnaires between November 2013 and November 2014 (Median months after childbirth (P25-P75): 4.3 (4.0-4.6)). After exclusion of the participants with $>20 \%$ of missing values on the QoL questionnaire, as recommended [31], 61 mothers and 56 fathers were included in the quantitative analysis.

Perceived QoL was assessed using the Portuguese version of the World Health Organization Quality of Life - BREF Inventory (WHOQOL-BREF) [32]. It is organized into a facet of overall QoL (general perception of QoL and health) and 4 domains: physical (pain and discomfort; energy and fatigue; sleep and rest; dependence on medication; mobility; activities of daily living; working capacity), psychological (positive and negative feelings; self-esteem; thinking, learning, memory and concentration; body image; spirituality, religion and personal beliefs), social relationships (personal relations; sexual activity; social support), and environment (financial resources; information and skills; recreation and leisure activities; home environment; accessibility and quality of health and social care; physical safety and security; physical environment; transport).

Data on sociodemographic characteristics were collected, as well as data regarding infants' length of stay in NICU and the presence of health problems. 
Occupations were classified according to the Portuguese Classification of Occupations 2010 [33] and grouped in three categories: upper-white-collar, including executive civil servants, industrial directors and executives, professionals and scientists, middle management and technicians; lower-white-collar, including administrative and related workers, service and sales workers; and blue-collar, which includes farmers and skilled agricultural, fisheries workers, skilled workers, craftsmen and similar, machine operators and assembly workers, unskilled workers. Unemployed $(n=15)$ or retired participants $(n=1)$ were classified considering their previous main occupation.

Symptoms of anxiety, depression and parenting stress were assessed through Portuguese versions of The Beck Anxiety Inventory [34], the Beck Depression Inventory-II [35], and The Parenting Stress Index (PSI) [36], respectively.

Participants were georeferenced according to the home address, using the ArcGIS Online World Geocoding Service and Google Maps. Each participant was matched to the urbanity level [37] and the neighbourhood socioeconomic deprivation, assessed through The European Deprivation Index [38].

\section{Statistical analysis}

Missing values of the WHOQOL-BREF inventory were replaced by means of the remaining domain items, when $\leq 2$ items were missing from the domains physical, psychological and environment and 1 item in the social relationships domain [31]. Regarding the BDI and BAI scores, participants with $>2$ items missing were discarded from the current analysis; the remaining missing values were replaced by the mean value for each item [35]. Missing values in the PSI were substituted using the subscale items if no more than 5 items from total scale, 3 items from each domain and 1 item from each subscale were missing [39].

The analysis was performed using Stata 11.0 (College Station, TX, 2009). The chi-square test and the t-test or the Mann-Whitney-test were used as appropriate. Linear regression models, stratified by gender, were computed to assess the association between participants' characteristics and the QoL. Statistical significance was set at a value of $p<.05$.

\section{Qualitative study: Participants and data collection}

Semi-structured qualitative interviews were conducted with a sub-sample of 26 couples between November 2013 and April 2014. Participants were purposively sampled to include parents of infants with extremely $(<1000 \mathrm{~g})$ and non-extremely ( $\geq 1000 \mathrm{~g}$ ) low birth weight. A heterogeneity sampling was used for maximum variation of views and experiences, until reaching thematic saturation. Therefore, recruitment continued until no new themes emerged from the interview data [40].
Interviews were conducted at parents' home $(n=19)$, at the university department responsible for the study $(n=6)$ and in a private hospital room $(n=1)$. Interview duration ranged from 20 to $72 \mathrm{~min}$ (Mean: $39 \mathrm{~min}$ ). All interviews were audio taped and transcribed verbatim. The interview guide covered the following areas: how parents deal with uncertainty and doubts and how they made their decisions concerning parental care, treatment options and uses of information sources; their views of the consent procedures; their understandings of medical facts, of technologies applied to perinatal care and of prognosis; their views of life and living with handicaps; information and communication needs of parents; and awareness of social and ethical issues in this area. Data related to parents' perceptions of their QoL will be discussed by exploring the entire content of each interview.

\section{Content analysis}

Thematic content analysis [41] was performed using the software NVivo 11 (QSR International, USA, 2015). A triangulation strategy was used to guarantee the rigour and quality of research - the first author identified, sentence by sentence, parents' perceptions about the factors influencing (positively and negatively) their QoL after a very preterm delivery, and the last author collaborated on the development of the coding framework. Firstly, quotations with similar meanings were synthesized into categories, both deductively, in accordance with the facets of the WHOQOL-100 inventory [31], and inductively for the remaining data. Secondly, the categories were grouped into the following analytical themes: the domains of the WHOQOL-BREF inventory (Physical, Psychological, Social relationships and Environment) [31] and "Accommodation mechanisms", corresponding to behavioural, cognitive, and emotional processes to accommodate a very preterm delivery [21]. The re-examination of qualitative data was performed when disagreements with quantitative results were found. The most illustrative verbatim quotes were selected by two authors and revised by an English native speaker.

\section{Results}

The characteristics of the parents who completed the questionnaire and their association with QoL are presented in Tables 1 and 2, respectively. The results are explored integrating quantitative and qualitative data, according to QoL domains.

\section{Overall QoL and accommodation mechanisms}

A quantitative analysis revealed that the perception of overall QoL was not significantly different by gender (Mean (SD): 74.6 (12.5) for mothers; 72.8 (12.4) for fathers). Higher levels of anxiety and depressive symptoms were negatively associated with the parental perception of overall QoL. Among mothers, having higher levels of 
Table 1 Characterization of the participants who filled in the questionnaire, according to gender

\begin{tabular}{|c|c|c|c|}
\hline & $\begin{array}{l}\text { Total } \\
n=117\end{array}$ & $\begin{array}{l}\text { Mothers } \\
n=61\end{array}$ & $\begin{array}{l}\text { Fathers } \\
n=56\end{array}$ \\
\hline Age < 35 years, $\mathrm{n}(\%)$ & $71(62.8)$ & $42(68.9)$ & $29(55.8)$ \\
\hline Educational level $\leq 12$ years, $\mathrm{n}(\%)$ & $69(60.5)$ & $34(55.7)$ & $35(66.0)$ \\
\hline Married/living with a partner, n (\%) & $105(92.1)$ & $56(91.8)$ & $49(92.5)$ \\
\hline \multicolumn{4}{|l|}{ Occupation ${ }^{\mathrm{a}}, \mathrm{n}(\%)$} \\
\hline Upper white collar & $46(42.2)$ & $22(37.9)^{*}$ & $24(47.1)^{*}$ \\
\hline Lower white collar & $32(29.4)$ & $25(43.1)^{*}$ & $7(13.7)^{*}$ \\
\hline Blue Collar & $31(28.4)$ & $11(19.0)^{*}$ & $20(39.2)^{*}$ \\
\hline Low/Medium-low subjective social class, n (\%) & $87(77.7)$ & $43(71.7)$ & $44(84.6)$ \\
\hline \multicolumn{4}{|l|}{ Neighbourhood socioeconomic deprivation, n (\%) } \\
\hline T1 (Least deprived) & $50(42.7)$ & $27(44.3)$ & $23(41.1)$ \\
\hline $\mathrm{T} 2$ & $38(32.5)$ & $20(32.8)$ & $18(32.1)$ \\
\hline T3 (Most deprived) & $29(24.8)$ & $14(23.0)$ & $15(26.8)$ \\
\hline \multicolumn{4}{|l|}{ Urbanity Level, n (\%) } \\
\hline Predominantly Rural/Moderately Urban & $15(12.8)$ & $8(13.1)$ & $7(12.5)$ \\
\hline Predominantly Urban & $102(87.2)$ & $53(86.9)$ & $49(87.5)$ \\
\hline \multicolumn{4}{|l|}{ Parenting stress } \\
\hline Total stress scale ${ }^{\mathrm{b}}$, Median (P25-P75) & $216.5(189.0-247.0)$ & $220.0(204.0-245.0)$ & $209.0(188.0-254.0)$ \\
\hline Stressful life events scalec, Median (P25-P75) & $10.0(4.0-15.0)$ & $11.0(4.0-19.0)$ & $10.0(4.0-15.0)$ \\
\hline Anxiety ${ }^{d}$, Median (P25-P75) & $3.0(1.0-7.0)$ & $3.0(1.0-7.7)$ & $2.0(1.0-5.0)$ \\
\hline Depressione, Median (P25-P75) & $4.0(2.0-8.0)$ & $6.0(3.0-9.0)^{*}$ & $3.5(1.0-6.0)^{*}$ \\
\hline Previous children, n (\%) & $29(26.1)$ & $16(26.2)$ & $13(26.0)$ \\
\hline Multiple pregnancy, n (\%) & $23(19.7)$ & $12(19.7)$ & $11(19.6)$ \\
\hline Pregnancy complications ${ }^{\mathrm{f}}, \mathrm{n}(\%)$ & $51(43.6)$ & $27(44.3)$ & $24(42.9)$ \\
\hline Extremely low birth weight delivery ${ }^{9}, \mathrm{n}(\%)$ & $33(28.2)$ & $18(29.5)$ & $15(26.8)$ \\
\hline Extremely preterm delivery, $\mathrm{n}(\%)$ & $24(20.5)$ & $13(21.3)$ & $11(19.6)$ \\
\hline NICU length of stay < 2 months, $n(\%)$ & $71(61.7)$ & $37(61.7)$ & $34(61.8)$ \\
\hline Infants' health problems', n (\%) & $25(21.4)$ & $15(24.6)$ & $10(17.9)$ \\
\hline \multicolumn{4}{|l|}{ Quality of life (WHOQOL-BREF) ${ }^{j}$} \\
\hline Overall, Mean (SD) & $73.7(12.4)$ & $74.6(12.5)$ & $72.8(12.4)$ \\
\hline Physical domain, Mean (SD) & $77.1(12.6)$ & $75.9(12.2)$ & $78.3(13.1)$ \\
\hline Psychological domain, Mean (SD) & $78.7(14.4)$ & $77.2(14.8)$ & $80.4(13.9)$ \\
\hline Social relationships domain, Mean (SD) & $75.1(17.1)$ & $75.8(17.9)$ & $74.3(16.4)$ \\
\hline Environment domain, Mean (SD) & $72.1(14.2)$ & $72.9(13.9)$ & $71.3(14.6)$ \\
\hline
\end{tabular}

${ }^{\mathrm{a} S t u d e n t s, ~ h o u s e w i v e s ~ a n d ~ a r m e d ~ f o r c e s ~ o c c u p a t i o n s ~ w e r e ~ e x c l u d e d ; ~}{ }^{\mathrm{b}}$ The total stress score is the sum of the scores in two domains: child's characteristics and parent's characteristics, with higher scores indicating higher levels of parental stress (range for the total scale: 104 to 517 ); ' 'Stressful Life Events scale is composed by 24 different life events likely to cause stress (e.g.: unemployment, divorce, death of a relative), with higher values indicating more stress in life (range for the total scale: 0 to 114); ${ }^{d}$ Higher values indicate higher levels of anxiety symptoms (range for the total scale: 0 to 63 ); ${ }^{\text {e Higher values indicate }}$

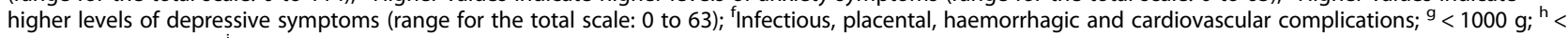
28 gestational weeks; 'Inguinal and umbilical hernias, metabolic disease, ovarian cysts, bronchial dysplasia, autoimmune disease, cardiac disease, congenital malformation; ${ }^{j}$ Higher values represent better QoL (Range: $\left.0-100\right)$

Notes: In each variable, the total may not add 117 parents, 61 mothers or 56 fathers due to missing values; The proportions may not add 100 due to rounding; SD, Standard Deviation; ${ }^{*} \mathrm{p}$ value $<.05$ for the comparison between mothers and fathers

total stress, higher stress life scores, an extremely low birth weight delivery and an infant with health problems or hospitalized in NICU for 2 months or more, was associated with worst overall QoL.

Four main mechanisms to accommodate the delivery of a very preterm infant on their lives were mentioned by the interviewed couples. Firstly, being optimistic by choosing to "be very practical" and "to think positive" (I26), despite being scared:

"Despite these little scares [cold, urinary tract infection and conjunctivitis], everything is going positively, it is going well." (I18) 


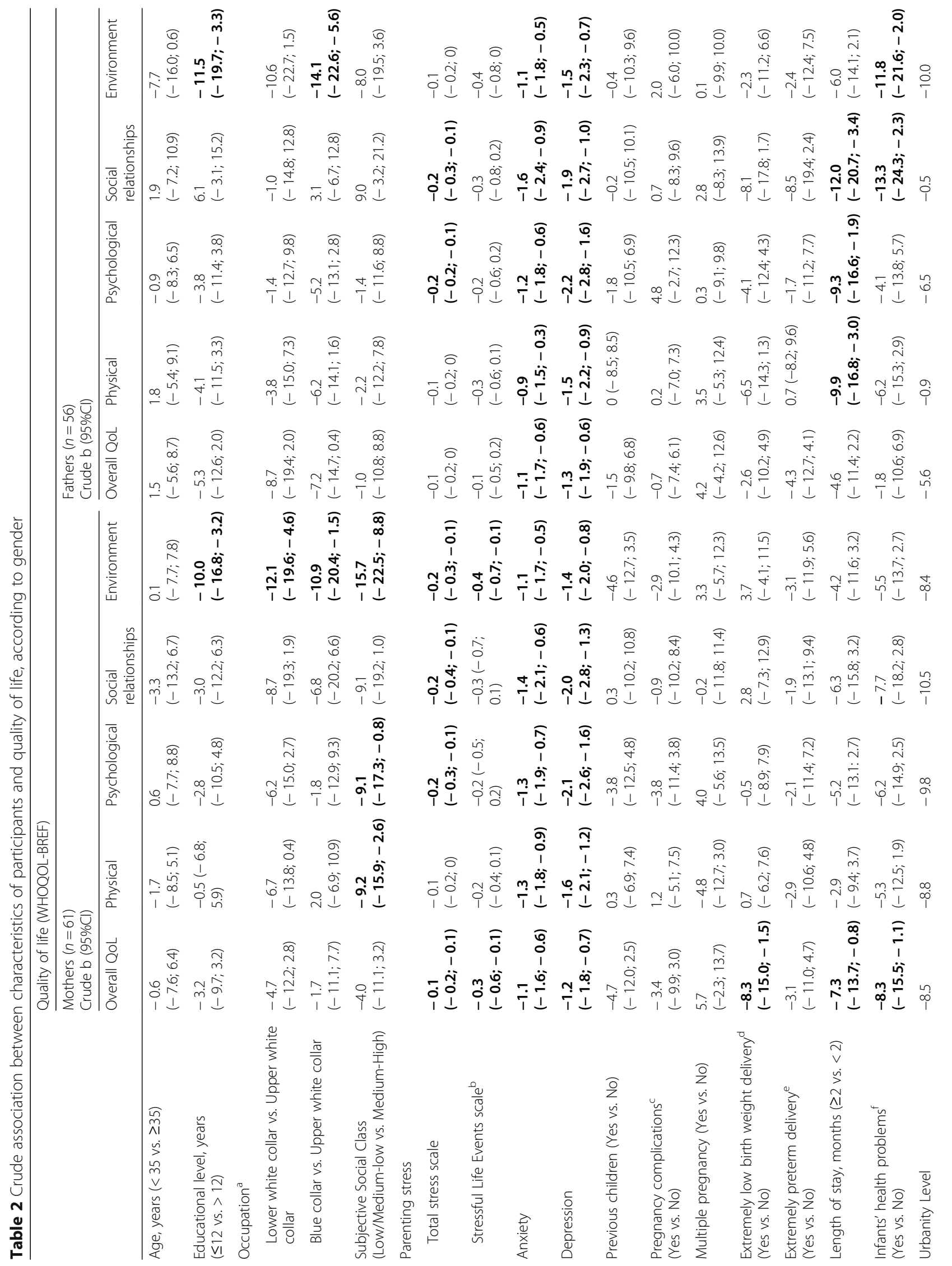




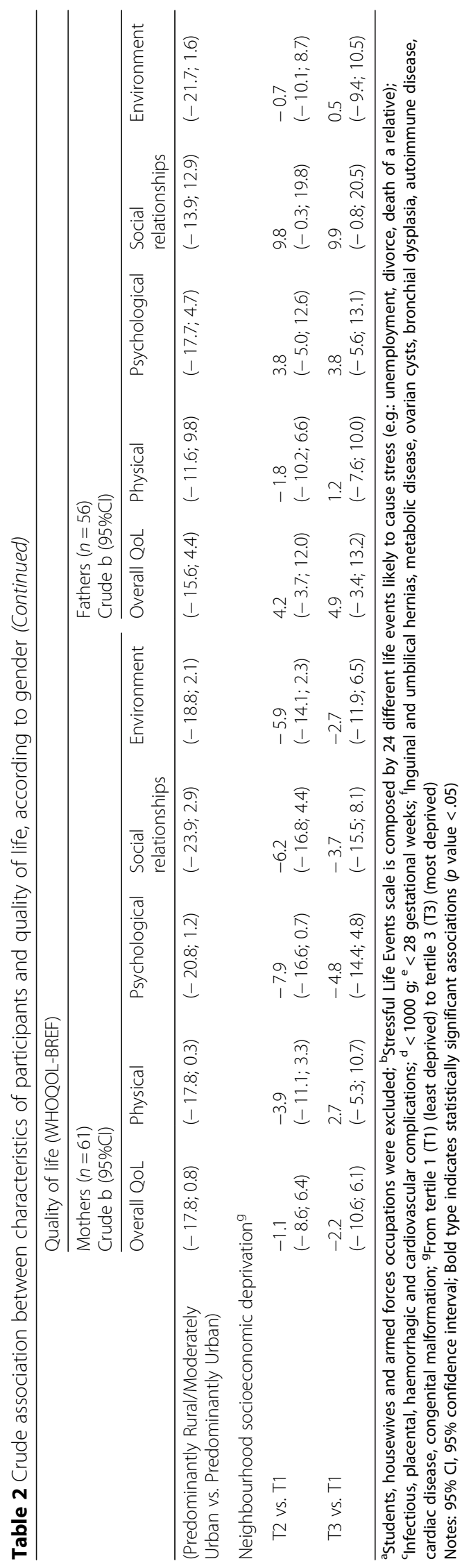


Secondly, reordering goals by giving priority to the infant and learning to devalue stressful "little things" while attributing more value "to the really important things" such as seeing the infant breathing autonomously:

"The little things that stress us on daily life (...) nowadays we devalued it, we attribute more value to the really important things (...) [like] seeing him [son] breathing for himself [without medical support] every day." (I2)

Thirdly, using comparisons between their infants and those with severe health problems to highlight how they are "lucky" (I2) and should "thank God" (I24). Lastly, reframing expectations about the current and future development of their infant helped parents to deal with the experience of parenting a very preterm infant:

"He [son] had some little problems (...) but it's nothing of concern in terms of development. (...) We can't expect that he, with 4 months, matches with a 4 months term baby." (I11)

"In the future, it [the concern] will be knowing if she [daughter] will develop the speaking skill (...) the growth we already know that it will be slow." (I13)

\section{Physical QoL}

Based on a quantitative analysis, physical QoL was slightly higher among fathers (Mean (SD): 78.3 (13.1) vs. 75.9 (12.2) for mothers). This perception was negatively associated with higher levels of anxiety and depressive symptoms among mothers and fathers. Physical QoL was lower among mothers from a lower subjective social class and among fathers of infants hospitalized in NICU for 2 months or more.

Interviewees only mentioned negative factors influencing their physical QoL. The main issues presented by the parents included sleep deprivation, nightmares and poor sleep quality, as well as unpredictability and lack of time to perform daily activities or organizing the house. Some interviewees considered the infant's dependence on medical substances and medical aids as "a daily challenge" (I19), and reported self-dependence of medication to manage headaches connected to the burden of parenting very preterm infants (I25). Few couples emphasized the deterioration of working capacity by feeling "lost [and] disorientated" to supervise employees (I17), as well as the discomfort experienced when pumping breast milk, seen as a "little sacrifice" for the child (I11), and the tiredness provoked by the intensive full-time caring of a very preterm infant:
"It's like a 24 out of 24 hours job and then the tiredness is different. (...) Because she is preterm, [the routine is] even more intense." (I24)

\section{Psychological QoL}

The highest quantitative score among the parental QoL domains was observed in the psychological domain among both mothers (Mean (SD): 77.2 (14.8)) and fathers (Mean (SD): 80.4 (13.9)). Lower levels of psychological QoL were associated with higher levels of parenting stress, anxiety and depression, for both mothers and fathers. This domain was also negatively associated with mother's lower subjective social class, and with having an infant hospitalized in NICU for 2 months or more among fathers.

Interviewees mentioned the surveillance as a major constraining factor to psychological QoL. Parents were aware of the burden caused by surveillance but revealed difficulties in overcoming their "instinctive" need to control all social interactions established with the baby and the environment, as well as their distrust on relatives and friends to take care of the infant:

\section{"[When other people hold my son] I usually stay like} "a security dog" (...) it's like an instinct." (I16)

"The environment is always controlled. (...) The house has to be clean every day. (...) We have thermometers all over the house." (I2)

"I can't leave my daughter (...) with anybody. (...) I don't know why." (I6)

Participants justified such difficulties by expressing negative feelings that involve fears and uncertainties around the return to the hospital, the infant's death or suffering or the infant's future development. A few interviewees also invoked thinking difficulties, a "completely loss of personal autonomy" related to the need to live according to their infants (I11) and mixed emotions:

\section{"It's a whirlwind of emotions, and it's a challenge} dealing with all that things." (I24)

"[Having a very preterm infant] means happiness, means torment, anxiety and joy." (I25)

Some respondents neutralized the negative influence of a very preterm delivery on psychological QoL by focusing on positive feelings, such as "joy" and "happiness", and assuring self-esteem based on self-confidence as "strong" women and "very careful and responsible" mothers. Additional strategies were related with enacting 
spirituality/religion and personal beliefs (e.g. considering that "things happen because they have to happen, and we have to face them" (I1)), as well as acquiring parental autonomy by learning how to administrate medical treatments at home:

Father: "We are more self-sufficient if we do the things [administrate injections] at home, so I have learnt to give the injection. We don't need to go out with him [son] to do this medical treatment."

Mother: "Neither we are dependent of other people." (I24)

\section{Social relationships QoL}

Mothers and fathers presented similar values of social QoL (Mean (SD): 75.8 (17.9); 74.3 (16.4), respectively). This domain was negatively associated with higher levels of parenting stress, anxiety and depressive symptoms among women and men. Fathers of infants hospitalized for 2 months or more and with health problems presented lower levels of social QoL.

In interviews, parents mentioned the benefits of pragmatic or emotional support provided by family, friends, healthcare providers or other parents of very preterm infants:

"We have my parents-in-law, and sometimes my parents, helping us to take care of him [son], for allowing us to do other things [washing the car, rest].” (I26)

"Now they [friends] are [acting] with normality, they are more positive (...) They try to relax us and transmit us security." (I21)

"If we [parents] don't know what to do we can call the NICU professionals of where he [son] was

[hospitalized] (...) anytime." (I8)

"Sometimes we [parents] call them [other NICU parents] and ask them how they dealt with baby's cramps. We talk to each other a lot of times." (I25)

Different perspectives toward personal relationships were reported: some couples stated that the very preterm childbirth strengthen their marital relationship, while others complained about the lack of time "for each other". Likewise, parents distinguished between supportive personal networks and those who criticize them:

"We feel a great understanding about our concerns with hygiene, I think we always felt they [family and friends] understand us and that they do everything to facilitate [our life].” (I12)
"We know that (...) a lot of people and family members criticize us because we are excessively careful [with the infant]." (I3)

\section{Environment QoL}

The lowest quantitative scores on parental QoL were observed in the environment domain (Mean (SD): 72.9 (13.9) among mothers; 71.3 (14.6) among fathers). They were negatively associated with lower levels of education, having blue-collar occupations and higher levels of anxiety and depressive symptoms for both parents. Among mothers, lower scores of environment QoL were also associated with having lower white-collar occupations, a low/medium-low subjective social class, higher levels of parenting stress and higher stress life scores. Fathers of infants with health problems scored worst on environment QoL.

Interviewees focused on the influence of the accessibility and quality of health and social care. Parents recognized government financial support for infant's healthcare, namely for hospitalization, medication and vaccination, and their satisfaction with medical services as enabling factors, but pointed the negative influence of non-supportive parental leave policies and family allowance, as well as lack of coverage of "special" milk and all vaccines that preterm babies need and the absence of a "fast track" for very preterm infants in the emergency room.

"Due to the infant prematurity, the parental leave should be extended, for both mother and father. (...) I would start working next month and she [daughter] needs special care at least for one year." (I20)

Some participants also mentioned the negative influence of the hygienization of bodies and spaces. The concern with the sterilisation of hands and objects and the avoidance of touch and closeness in the relationships with the infant adversely affected their QoL:

Father: "The care with sterilization of hands (...) [and] for not kissing him [son] - perhaps if he was a normal baby there are things that we didn't going through."

Mother: "If something drops to the floor, it goes immediately to the laundry." (I2)

"At the entrance room, they [visits] have to put the mask on and to wash and sterilise the hands and they're only allowed to see the baby, nobody can touch her [daughter]." (I20)

Other issues presented by the interviewees included constraints on their participation in recreation and 
leisure activities. They often referred to isolation and the absence of a "social life" as threatening their QoL. A few participants overcome these by taking advantage of opportunities to share "enjoyable" moments together, such as "watching a movie or talking to each other" (I12). A few couples also reported different perspectives regarding the home environment and financial resources by combining their negative and positive influence on QoL in a hybrid way. The need to rearrange small home spaces due to their infant's medical needs, like " $a$ medical oxygen cylinder" (I19), to become aware of their family's inability to fulfil infant's needs due to financial constraints and lack of support in transportation "for taking the infant to the clinical appointments" (I9) contributed to deteriorate QoL, while the access to conditions for creating a "calm environment" in the household and to financial resources positively affected QoL.

Some participants highlighted how the opportunities for acquiring new information and skills improved their sense of competence and control at home. These opportunities occurred either during infant's hospitalisation in NICU through the "intensive course" provided by health professionals or outside NICU by being offered the opportunity to clarify doubts about the baby by the paediatrician:

"We learned a lot [in NICU]. (...) It was there the father changed the first diaper, gave the first bath... He came home very prepared. (...) We used to say that it was an intensive course." (I18)
"For us the most important thing is (...) having a person [health professional] to contact (...) anytime to clarify our doubts." (I5)

\section{Discussion}

Quantitative data suggest that mothers and fathers of very preterm infants present similar values of QoL, increasing slightly from the environment to the psychological domain. Parenting stress, anxiety or depressive symptoms negatively influence both maternal and paternal QoL, while the impact of socioeconomic position and infant-related factors (NICU length of stay, health problems and extremely low birth weight delivery) varies according to gender and QoL domains. Qualitative findings highlight constraining factors related with surveillance, non-supportive healthcare policies and the need for hygienization, and protective factors as social support, accessibility and quality of healthcare, and opportunities for developing parental skills.

Participants' quantitative assessment of QoL is comparable to the scores observed in the Portuguese general population [32, 42, 43], reinforcing previous findings showing that there are no differences in QoL between parents of very low birth weight infants and the general population [44]. The negative association between depressive [11] or psychiatric symptoms [10] and QoL among mothers and caregivers of preterm infants has also been reported previously, as well as the influence of socioeconomic position [45]. Moreover, the stress-

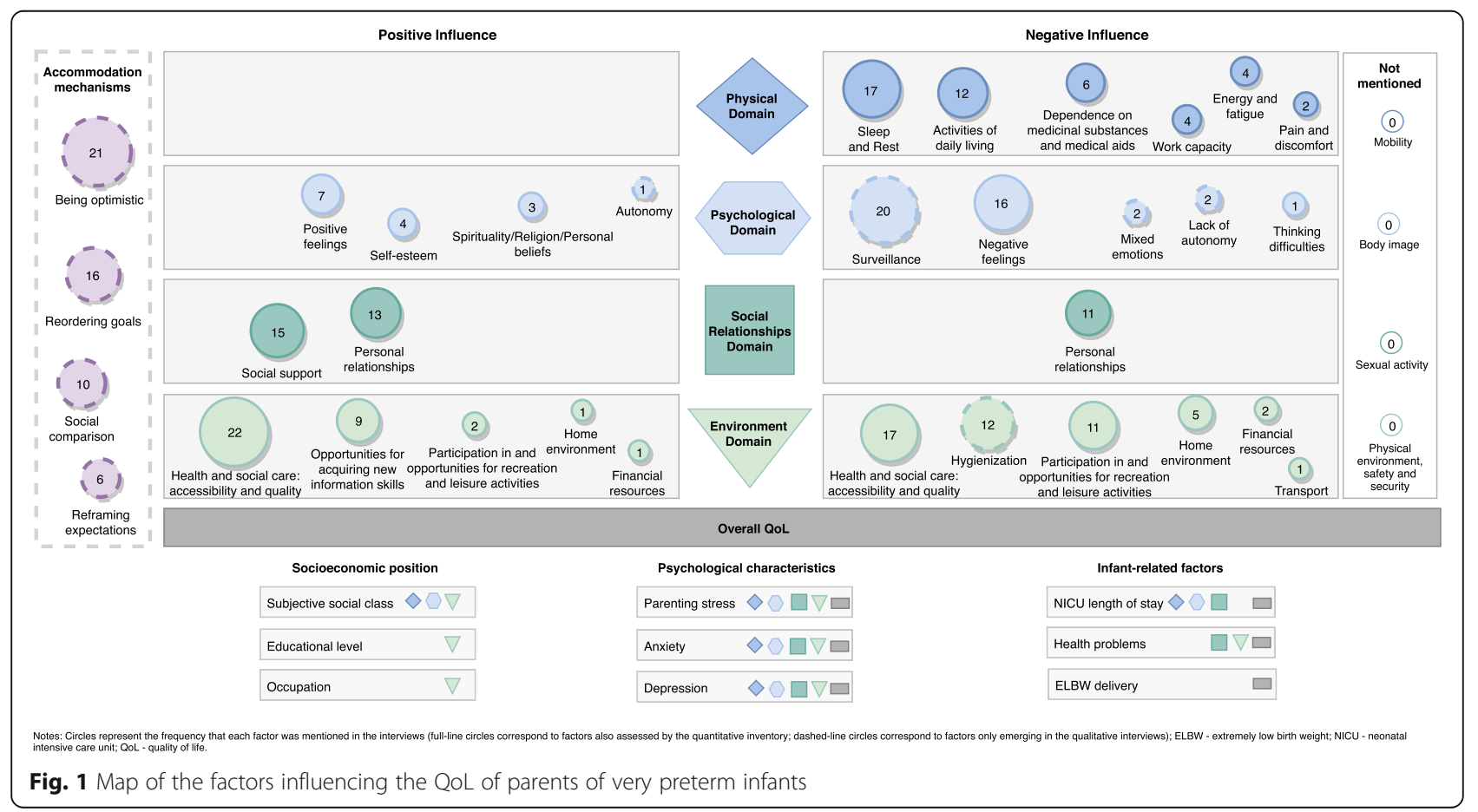


buffering effects of social support [46] and the positive impact of family-friendly and gender-equality policies $[9,47]$ on QoL are widely recognized.

This study adds to the literature the idea that similar quantitative scores of QoL might hide social inequalities and translate different meanings behind QoL. Figure 1 represents a comparison matrix in which a side-by-side joint display is used to converge the quantitative and qualitative data. First, each item assessed by the quantitative instrument does not acquire the same relative weight in parents' narratives. Second, there are facets assessed by the survey not mentioned by interviewees (mobility, body image, sexual activity, physical environment, safety and security). Third, parents mention several issues during the interviews that are not addressed by the questionnaire (such as the constant surveillance, hygienization of bodies and spaces, experience of mixed emotions, and lack of autonomy as negatively influencing their QoL). Bringing together the differing but complementing strengths of quantitative methods (e.g., trends and generalization) with those of qualitative methods (e.g. in-depth description and details) in a one-phase design might thus contribute to develop a specific quantitative tool to sensitively assess QoL of parents of very preterm infants, while helps to better understand their underlying factors.

When experiencing a very preterm childbirth, parents adjusted their expectations and changed their internal standards to accommodate such a catalyst event in their lives [21], as reported in studies with chronic illnesses patients [48]. The accommodation mechanisms observed in this study (being optimistic, reordering goals, social comparison and reframing expectations) are anchored in child-centredness, reflecting the incorporation of intensive parenting social norms and leading to the prioritization of child's health and well-being over parents' QoL [49], and in a pragmatic framework that construct hierarchies of hope [44] and expectations about infant's health status and development.

Couple interviews may have limited emergence of some facets assessed by the survey, in particular those related with body image and sexual activity. Interviewed parents may have felt uncomfortable acknowledging these issues in couple. In addition, the possibility of assuming as taken for granted facets as physical environment, safety and security cannot be excluded, as demonstrated by the quantitative rates. Further studies should explore the meanings attributed to each of these facets, discussing the implications for the assessment of the QoL.

These achievements reinforce the idea that the use of generic instruments may not be sensitive enough to accurately capture the specificities and idiosyncrasies of parents of very preterm infants $[25,50]$, overestimating their QoL. However, to acknowledge an individual holistic assessment that considers spirituality, religion and personal beliefs in QoL measurements is a step forward to improve the sensitivity of quantitative instruments, especially in health context [51-53]. Still, there is a need for further research on the development of a new quantitative tool specifically designed for being used to assess QoL among parents of very preterm infants.

The use of a convergent mixed methods design is a strength of this study, in which the inclusion of researchers who have quantitative and qualitative expertise addressed the effort to offer equal weight to two type of data. The sample size and the response rate could limit the power to detect small but potentially important differences, but they are quite similar to those observed in other studies with comparable populations and objectives [14, 54]. Moreover, there are no significant differences between participants who returned the questionnaire and those who did not regarding all the assessed variables except for marital status. Participants are more likely to be married or living with a partner (92.1\% vs. $82.9 \%$ among non-participants, $p=.044)$, which could cause some bias, since married people are more likely to score higher in the QoL questionnaires than people with other marital status $[14,55]$.

\section{Conclusions}

This study raises awareness for the need to capture the QoL of parents of very preterm infants using a mixed-methods approach for developing intersectoral family-centred public policies, integrated healthcare services on prematurity and focused-interventions to decrease the disempowering effects of surveillance and hygienization.

\section{Abbreviations}

NICU: Neonatal Intensive Care Unit; QoL: Quality of Life; WHOQOLBREF: World Health Organization Quality of Life - BREF Inventory

\section{Acknowledgements}

We thank all participants and health professionals for their collaboration in the study.

\section{Funding}

This study was co-funded by national funding from the Foundation for Science and Technology - FCT (Portuguese Ministry of Science, Technology and Higher Education), the FEDER funding from the Operational Programme Factors of Competitiveness - COMPETE and POPH/FSE Program, under the Unidade de Investigação em Epidemiologia - Instituto de Saúde Pública da Universidade do Porto (EPIUnit) (POCI-01-0145-FEDER-006862; Ref. FCT UID/ DTP/04750/2013), the project "Parenting roles and knowledge in Neonatal Intensive Care Units" (FCOMP-01-0124-FEDER-019902; Ref. FCT PTDC/CS-ECS/ 120750/2010), the PhD grant PD/BD/105830/2014 (MA), the Postdoc grant SFRH/BPD/103562/2014 (EA), and the FCT Investigator contract IF/01674/ 2015 (SS).

\section{Availability of data and materials}

The datasets generated and/or analysed during the current study are not publicly available due to a confidentiality agreement securing participants' privacy and anonymity but are available from the corresponding author on reasonable request. 


\section{Authors' contributions}

MA, EA and SS collaborated in the acquisition, analysis and interpretation of the data. MA drafted the article. EA, MKI, AIR and SS reviewed the article critically for important intellectual content. All authors read and approved the final manuscript.

\section{Ethics approval and consent to participate}

The study was approved by the National Data Protection Commission and the Ethics Committee of all hospitals where the data was collected. Informed consent was obtained from all individual participants included in the study.

\section{Consent for publication}

Not applicable.

\section{Competing interests}

The authors declare that they have no competing interests.

\section{Publisher's Note}

Springer Nature remains neutral with regard to jurisdictional claims in published maps and institutional affiliations.

\section{Author details}

'EPIUnit - Instituto de Saúde Pública, Universidade do Porto, Rua das Taipas, n 135, 4050-600 Porto, Portugal. ²Departamento de Ciências da Saúde Pública e Forenses e Educação Médica, Faculdade de Medicina, Universidade do Porto, Al. Prof. Hernâni Monteiro, 4200 - 319 Porto, Portugal. ${ }^{3}$ Global Public Health Doctoral Programme, Porto, Portugal. ${ }^{4}$ INSERM UMR1027, F-31000 Toulouse, France. ${ }^{5}$ Université Toulouse III Paul Sabatier, UMR1027, F-31000 Toulouse, France.

Received: 28 June 2018 Accepted: 4 September 2018 Published online: 10 September 2018

\section{References}

1. GBD 2015 Child Mortality Collaborators. Global, regional, national, and selected subnational levels of stillbirths, neonatal, infant, and under-5 mortality, 1980-2015: a systematic analysis for the Global Burden of Disease Study 2015. Lancet. 2016;388:1725-74.

2. McCormick MC, Litt JS, Smith VC, Zupancic JA. Prematurity: an overview and public health implications. Annu Rev Public Health. 2011;32:367-79.

3. Blencowe $\mathrm{H}$, Cousens $\mathrm{S}$, Oestergaard MZ, Chou D, Moller A-B, Narwal R, Adler $A$, et al. National, regional, and worldwide estimates of preterm birth rates in the year 2010 with time trends since 1990 for selected countries: a systematic analysis and implications. Lancet. 2012;379:2162-72.

4. March of Dimes, PMNCH, Save the children, WHO: Born Too Soon. In: Howson CP, Kinney MV, Lawn JE, editors. The global action report on preterm birth. Geneva: World Health Organization; 2012.

5. Zeitlin J, Draper ES, Kollee L, Milligan D, Boerch K, Agostino R, Gortner L, et al. Differences in rates and short-term outcome of live births before 32 weeks of gestation in Europe in 2003: results from the MOSAIC cohort. Pediatrics. 2008:121:e936-44.

6. Milligan DW. Outcomes of children born very preterm in Europe. Arch Dis Child Fetal Neonatal Ed. 2010:95:F234-40.

7. Jubinville J, Newburn-Cook C, Hegadoren K, Lacaze-Masmonteil T. Symptoms of acute stress disorder in mothers of premature infants. Adv Neonatal Care. 2012;12:246-53

8. Treyvaud K. Parent and family outcomes following very preterm or very low birth weight birth: a review. Semin Fetal Neonatal Med. 2014;19:131-5.

9. Hansen T. Parenthood and happiness: a review of folk theories versus empirical evidence. Soc Indic Res. 2012;108:29-64.

10. Donohue PK, Maurin E, Kimzey L, Allen MC, Strobino D. Quality of life of caregivers of very low-birthweight infants. Birth. 2008;35:212-9.

11. Lee SY, Grantham CH, Shelton S, Meaney-Delman D. Does activity matter: an exploratory study among mothers with preterm infants? Arch Womens Ment Health. 2012;15:185-92

12. Lee SY, Hsu HC. Stress and health-related well-being among mothers with a low birth weight infant: the role of sleep. Soc Sci Med. 2012;74:958-65.

13. Lee SY, Kimble LP. Impaired sleep and well-being in mothers with lowbirth-weight infants. J Obstet Gynecol Neonatal Nurs. 2009;38:676-85.

14. Moura MR, Araujo CG, Prado MM, Paro HB, Pinto RM, Abdallah VO, Mendonca TM, Silva CH. Factors associated with the quality of life of mothers of preterm infants with very low birth weight: a 3-year follow-up study. Qual Life Res. 2017;26:1349-60.

15. Rivers A, Caron B, Hack M. Experience of families with very low birthweight children with neurologic sequelae. Clin Pediatr. 1987;26:223-30.

16. O'Brien K, Bracht M, MacDonell K, McBride T, Robson K, O'Leary L. A pilot cohort analytic study of Family Integrated Care in a Canadian neonatal intensive care unit. BMC Pregnancy Childbirth. 2013;13(Suppl 1):S12.

17. O'Brien K, Bracht M, Robson K, Ye XY, Mirea L, Cruz M, Ng E, Monterrosa L, Soraisham A, Alvaro R, et al. Evaluation of the family integrated care model of neonatal intensive care: a cluster randomized controlled trial in Canada and Australia. BMC Pediatr. 2015;15:210.

18. O'Brien K, Robson K, Bracht M, Cruz M, Lui K, Alvaro R, Silva O, Monterrosa L, Narvey $\mathrm{M}, \mathrm{Ng} \mathrm{E}$, et al. Effectiveness of family integrated care in neonatal intensive care units on infant and parent outcomes: a multicentre, multinational, clusterrandomised controlled trial. Lancet Child Adolesc Health. 2018;2:245-54

19. Cooper LG, Gooding JS, Gallagher J, Sternesky L, Ledsky R, Berns SD. Impact of a family-centered care initiative on NICU care, staff and families. J Perinatol. 2007;27(Suppl 2):S32-7.

20. American Academy of Pediatrics - Commitee on hospital care and institute for patient and family-centered care. Patient- and Family-Centered Care and the Pediatrician's Role. Pediatrics. 2012:129:394-404.

21. Sprangers MA, Schwartz CE. Integrating response shift into healthrelated quality of life research: a theoretical model. Soc Sci Med. 1999; 48:1507-15

22. Amorim M, Silva S, Kelly-Irving M, Alves E. Quality of life among parents of preterm infants: a scoping review. Qual Life Res. 2018:27:1119-31.

23. Amorim M, Alves E, Barros H, Silva S. Regulation of parental leave among parents of very preterm infants. Acta Med Port. 2015:28:281-2.

24. Spiteri G, Xuereb RB. Going back to work after childbirth: women's lived experiences. J Reprod Infant Psychol. 2012:30:201-16.

25. Mogos MF, August EM, Salinas-Miranda AA, Sultan DH, Salihu HM. A systematic review of quality of life measures in pregnant and postpartum mothers. Appl Res Qual Life. 2013;8:219-50.

26. Klassen AC, Creswell J, Plano Clark VL, Smith KC, Meissner HI. Best practices in mixed methods for quality of life research. Qual Life Res. 2012;21:377-80.

27. Creswell JW. A concise introduction to mixed methods research. Thousand Oaks: Sage Publications, Inc; 2015

28. NIH Office of Behavioral and Social Science. Best practice for mixed methods research in the health sciences. 2nd ed. Bethesda: National institutes of Health; 2018.

29. Alves $E$, Amorim M, Fraga S, Barros H, Silva S. Parenting roles and knowledge in neonatal intensive care units: protocol of a mixed methods study. BMJ Open. 2014:4:e005941.

30. World Health Organization. International statistical classification of diseases and related health problems. 10th ed. Geneva: World Health Organization; 2011.

31. World Health Organization, division of mental health and prevention of substance abuse. WHOOOL user manual. Geneva: World Health Organization; 1998.

32. Vaz-Serra A, Canavarro MC, Simões MR, Pereira M, Gameiro S, Quartilho M, et al. Estudos psicométricos do instrumento de avaliação da qualidade de vida da Organização Mundial de Saúde (WHOQOL-Bref) para Português de Portugal. Psiquiatria Clínica. 2006;27:41-9.

33. Statistics Portugal. Portuguese Classification of Occupations 2010. 2011. https://www.ine.pt/xportal/xmain?xpid=INE\&xpgid=ine_ publicacoes\&PUBLICACOESpub boui $=107961853 \&$ PUBLICACOESmodo $=$ 2\&xlang=en . Accessed 26 June 2018

34. Quintão S, Delgado AR, Prieto G. Validity study of the Beck anxiety inventory (Portuguese version) by the Rasch rating scale model. Psicol Reflex Crit. 2013;26:305-10

35. Campos RC, Gonçalves B. The Portuguese version of the Beck depression inventory-II (BDI-II): preliminary psychometric data with two nonclinical samples. Eur J Psychol Assess. 2011:27:258-64.

36. Abidin R, Santos S. Manual do PSI - Índice de Stress Parental. 2a ed. revista e acrescentada. Lisboa: CEGOC; 2014

37. Statistics Portugal. Administrative division. https://www.ine.pt/xportal/ xmain?xpid=INE\&xpgid=ine_cont_inst\&INST=6251013\&xlang=pt. Accessed 26 June 2018

38. Ribeiro Al, Mayer A, Miranda A, Pina MF. The Portuguese version of the European Deprivation Index: an instrument to study health inequalities. Acta Med Port. 2017:30:17-25.

39. Abidin R. Parenting stress index: professional manual. 4th ed. Lutz: PAR; 2012 
40. Patton MQ. Qualitative research \& evaluation methods. 4th ed. Thousand Oaks: SAGE publications, Inc; 2015.

41. Braun V, Clarke V. Using thematic analysis in psychology. Qual Res Psychol. 2006:3:77-101

42. Patrício B, Jesus LMT, Cruice M, Hall A. Quality of life predictors and normative data. Soc Indic Res. 2014;119:1557-70.

43. Gameiro S, Carona C, Silva S, Canavarro MC. Qualidade de vida e depressão: Um estudo comparativo com doentes com diagnóstico clínico de depressão major, utentes de centros de saúde e indivíduos da população geral. In: Canavarro MC, Vaz-Serra A, editors. Qualidade de vida e saúde: Uma abordagem na perspectiva da Organização Mundial de Saúde. Lisboa: Fundação Calouste Gulbenkian; 2010. p. 299-324.

44. Nordheim T, Rustoen T, Solevag AL, Smastuen MC, Nakstad B. Hope in parents of very-low birth weight infants and its association with parenting stress and quality of life. J Pediatr Nurs. 2018:38:e53-8.

45. Choi Y, Kim JH, Park EC. The effect of subjective and objective social class on health-related quality of life: new paradigm using longitudinal analysis. Health Qual Life Outcomes. 2015;13:121.

46. Gallicchio L, Hoffman SC, Helzlsouer KJ. The relationship between gender, social support, and health-related quality of life in a community-based study in Washington County, Maryland. Qual Life Res. 2007;16:777-86.

47. Lakshmanan A, Agni M, Lieu T, Fleegler E, Kipke M, Friedlich PS, McCormick MC, et al. The impact of preterm birth <37 weeks on parents and families: a cross-sectional study in the 2 years after discharge from the neonatal intensive care unit. Health Qual Life Outcomes. 2017;15:38.

48. Frazer MS, Mobley P. A mixed methods analysis of quality of life among late-life patients diagnosed with chronic illnesses. Health Qual Life Outcomes. 2017;15:222

49. Susan EB. Intensive performances of mothering: a sociological perspective. Qual Res. 2004:4:45-75.

50. Chen TH, Li L, Kochen MM. A systematic review: how to choose appropriate health-related quality of life (HRQOL) measures in routine general practice? J Zhejiang Univ Sci. 2005;6B:936-40.

51. WHOQOL SRPB Group. A cross-cultural study of spirituality, religion, and personal beliefs as components of quality of life. Soc Sci Med. 2006;62:1486-97.

52. Catré MNC, Ferreira JA, Pessoa T, Catré A, Catré MC, Pereira M. Desenvolvimento e Características Psicométricas das Facetas Adicionais da Versão em Português Europeu do WHOQOL-SRPB (Spirituality, religiousness and personal beliefs). Revista Portuguesa de Pedagogia. 2017;51:73-98.

53. Catré MNC, Ferreira JA, Pessoa T, Pereira M, Canavarro MC, Catré A. O domínio SRPB (Spirituality, Religiousness and Personal Beliefs) do WHOQOL: O estudo com grupos focais para validação da versão em Português europeu do WHOQOL-SRPB. Análise Psicológica. 2014;4:401-17.

54. Gameiro S, Nazaré B, Fonseca A, Moura-Ramos M, Canavarro MC. Changes in marital congruence and quality of life across the transition to parenthood in couples who conceived spontaneously or with assisted reproductive technologies. Fertil Steril. 2011;96:1457-62.

55. Han KT, Park EC, Kim JH, Kim SJ, Park S. Is marital status associated with quality of life? Health Qual Life Outcomes. 2014;12:109.

Ready to submit your research? Choose BMC and benefit from:

- fast, convenient online submission

- thorough peer review by experienced researchers in your field

- rapid publication on acceptance

- support for research data, including large and complex data types

- gold Open Access which fosters wider collaboration and increased citations

- maximum visibility for your research: over $100 \mathrm{M}$ website views per year

At BMC, research is always in progress.

Learn more biomedcentral.com/submissions 